\title{
焼結体の粒度・軸比分布のモンテカルロ法による解析方法
}

\author{
小谷岳生 $*$ ・井上雅博 $* *$ ・新原晧一 \\ 大阪大学産業科学研究所, 567 茨木市美穂ヶ丘 8-1 \\ *大阪大学基礎工学部物性物理工学科, 560 豊中市待兼山町 1-1 \\ **東京工業大学工業材料研究所, 227 横浜市緑区長津田町 4259
}

\section{An Analytic Procedure for Evaluating Grain-Size and Grain-Aspect-Ratio Distribution in Polycrystalline Sintered Bodies Based on Monte Carlo Simulation}

Takao KOTANI*, Masahiro INOUE** and Koichi NIIHARA

The Institute of Scientific and Industrial Research, Osaka University, 8-1, Mihogaoka, Ibaraki-shi 567

*Department of Material Physics, Faculty of Engineering Science, Osaka University, 1-1, Machikaneyama-cho, Toyonaka-shi

** Reserch Laboratry of Engineering Materials, Tokyo Institute of Technology, 4259, Nagatsuta-cho, Midori-ku, Yokohama-shi

[Received March 11, 1992; Accepted July 8, 1992]

\begin{abstract}
A method for estimating the grain-size and grainaspect-ratio distributions in polycrystalline sintered bodies has been developed. We assume that grains are ellipsoids specified by three radii and that the radii distribution obeys to a probability-distribution function expressed with four distribution parameters. As a function of the four parameters, the area and the aspect-ratio histograms of the grain cross-sections of a sintered-body cross-section can be calculated by a Monte Carlo simulation method. The distribution parameter values are determined so that the calculated histograms conform to the observed ones by iterative calculation. We apply this analysis to the observed histograms about two kinds of alumina, obtained by using an image analyzer. The calculated histograms agree with the observed ones fairly well.
\end{abstract}

Key-words : Stereology, Grain size, Aspect-ratio, Ellipsoid, Cross-section, Histogram, Monte Carlo

\section{1. 緒 言}

焼結体の組織は，一見複雑ではあるが，統計的にはいく つかの「組織の指数」と呼べる量で，その組織を規定でき ると考えられる．材料の示す特性は, その組織により決定 されるので, 上記の「組織の指数」の関数として与えられ るはずである. 本研究では, ワイブル係数や電気的特性な ぞを決める重要な因子の一つと考えられる, 粒子の形状分 布及び体積の分布を規定する指数について考える.

以前には, 焼結体を構成する粒子を球形である等, 形状 を仮定した上で粒子の体積分布を, 粒断面積の分布より求 める方法が考案されている1) 3).これらの方法では粒子 を指定するパラメーターは, 体積に対応するものが一つし かない. 本研究では粒子の形状として三本の軸の長さの違 う一般的な棈円体を仮定する. 更に, その軸半径 $A, B, C$ に関する確率密度分布関数を 4 個の分布パラメーターを 持つ適切な形に仮定する. この仮定下で, モンテカルロ法 により，粒断面に関する軸比及び面積のヒストグラムを， その分布パラメーターの関数として計算することが可能で
ある。

著者らは, 出発原料の異なる 2 種類のアルミナ試料に ついて画像処理装置を用いて粒断面の軸比及び面積を計測 し，ヒストグラムを作成した，そして，このヒストグラム が上述の計算により求めたものと一致するように分布パラ メーターを決定した。

\section{2. 実験及び解析の方法}

\section{$2.1 \mathrm{Al}_{2} \mathrm{O}_{3}$ 焼結体の作製と粒断面の測定}

本研究では, 出発原料として $\alpha-\mathrm{Al}_{2} \mathrm{O}_{3}$ (住友化学製, $\mathrm{AKP} 30$ ) と $\gamma-\mathrm{Al}_{2} \mathrm{O}_{3}$ (旭化成製) の微粉末を用いた。この 2 種類の粉末を $\mathrm{N}_{2}$ 雲囲気中, 温度 $1400^{\circ} \mathrm{C}$, 圧力 $30 \mathrm{MPa}$, 保持時間 $1 \mathrm{~h}\left(\alpha-\mathrm{Al}_{2} \mathrm{O}_{3}\right.$; 以下試料 $\left.\mathrm{A}\right)$ 及び $3 \mathrm{~h}\left(\gamma-\mathrm{Al}_{2} \mathrm{O}_{3}\right.$; 以下試料 B）の条件でホットプレス焼結した。 $\gamma-\mathrm{Al}_{2} \mathrm{O}_{3}$ か ら出発した試料については, $\gamma \rightarrow \alpha$ 相転移が完全に終了し, 構成相が $\alpha-\mathrm{Al}_{2} \mathrm{O}_{3}$ のみであることを $\mathrm{X}$ 線回折により確認 した．また，これら二つの試料の密度をアルキメデス法に より測定したところ，いずれも相対密度 $99.5 \%$ の緻密な焼 結体であった.

次にこのホットプレス焼結体を鏡面研磨し，大気中， $1350^{\circ} \mathrm{C}$ の条件で熱エッチ後, 微細組織を走査型電子顕微 鏡（SEM）で撮影した。このSEM 写真を用い，OHP シ一トに粒界を写し取った。これから画像処理装置（ピア 又製，LA-500）により各粒断面に対する等価だ円の長半 径と短半径 $(a, b)$ を計測し $(a>b), s=\ln (a b)$ 及び $t=\ln (a / b)$ に関するヒストグラムを作成した（以下，Observed Histograms と呼ぶ).

\section{2 解析の方法}

上記の Observed Histograms より，「実際の粒子がどの ような体積, 形状分布をなすか？」を知ることが目的であ る．仮定したことは，以下の 2 点である.

（Ｉ）焼結体を構成する各粒子は，図１のようなだ円体 （3 本の軸半径を $A, B, C$ とする）により十分よく表され るとする。

（II）この軸半径 $A, B, C$ に関する分布関数は，以下の 


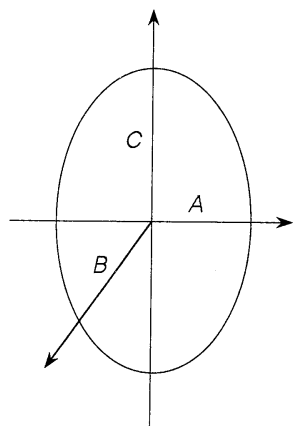

Fig. 1. The grains are assumed as ellipsoids.

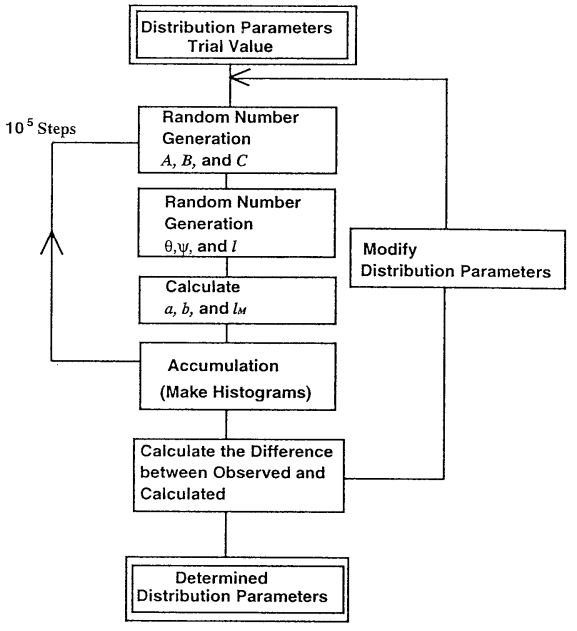

Fig. 2. Flow chart of the calculation to determine four distribution parameters. The four parameters specify the distribution of the grain-half radii $A, B$, and $C . \theta, \psi$, and $l$ specify how the grain cross a plain. $a$ and $b$ are the long and the short radii of the grain cross-section. $l_{\mathrm{M}}$ is the weight of the Monte Carlo step. The number of Monte Calro step is $10^{5}$.

2.3節で論述するような考察から, 下記の (1) 式の分布関数 で表されるとする（4 個の分布パラメーターを持つ）.

これらの仮定下で, コンピューターによる乱数発生の手 法により，上記の 4 個の分布パラメーターに対して，焼 結体断面における $s$ 及び $t$ に関して期待されるヒストグラ ム（以下，Calculated Histograms と呼ぶ）が計算できる （配向性はないとする）。著者らは，Observed Histograms $\approx$ Calculated Histograms となるように分布パ ラメーターを，収束計算により決定した。計算の流れを図 2 に，プログラム作成の詳細を付録に示した.

\section{3 粒子軸半径の分布関数}

従来，粒子の体積分布は対数正規分布，すなわち $S=\ln (A B C)$ に関する正規分布，でよく表されるとされ ている1).これを一般化して, $\ln (A), \ln (B), \ln (C)$ に関 する分布関数として，これらの 2 次関数が指数関数の肩 に乗った形のものを探すことにする. 以下，独立変数とし て, $\ln (A), \ln (B), \ln (C)$ の代わりに, $S$ 及び軸比の対数 $T_{1}=\ln (C / A)$ と $T_{2}=\ln (C / B)$ を用いる. 簡単化のため, 粒形状の分布と粒体積の分布は独立していると仮定すると
指数関数の肩は $S$ の 2 次関数と $T_{1}, T_{2}$ の 2 次関数の和々 なる. 粒形状分布を決める $T_{1}, T_{2}$ の 2 次関数の部分につ いては，これを０とおいたときに， $C / A=C / B=Q_{0}$ とな るように要請する.これは, 平均的な粒形状として軸比が $Q_{0}$ の，ラグビーボール型 $\left(Q_{0}>1\right)$ もしくはミカン型 $\left(Q_{0}<1\right)$ の粒子を仮定していることを意味する.

これらの条件を満たすものとして, $\mathrm{d} S \mathrm{~d} T_{1} \mathrm{~d} T_{2}$ 内にある 粒子数の割合が，

$\mathrm{P}\left(S, T_{1}, T_{2}\right) \mathrm{d} S \mathrm{~d} T_{1} \mathrm{~d} T_{2}$

$=\frac{1}{N} \exp \left(-\frac{\left(S-\ln \left(V_{0}\right)\right)^{2}}{2 \sigma_{V}^{2}}\right)$

$$
\begin{aligned}
& \times \exp \left(-\frac{\left(T_{1}-\ln Q_{0}\right)^{2}+\left(T_{2}-\ln Q_{0}\right)^{2}+\left(T_{1}-T_{2}\right)^{2}}{2 \sigma_{Q}{ }^{2}}\right) \\
& \times \mathrm{d} S \mathrm{~d} T_{1} \mathrm{~d} T_{2}
\end{aligned}
$$

で表されるものと仮定する．この分布関数の始めの部分が 粒体積分布に関する因子で文献1)などで論じられている もの，次が粒形状分布に関する因子であり本研究で新たに 付け加えたものである. $V_{0}$ は $A B C$ の平均値に， $Q_{0}$ は上 述の意味で平均粒形状に対応するパラメーターである.

$\sigma_{V}, \sigma_{Q}$ は，粒体積のばらつき，粒形状のばらつきに対応 するパラメーターであり $S$ あるいは $T_{1}, T_{2}$ が平均值から ずれる程度を示す． $N$ は規格化定数である．なお，各粒 子の軸半径の三個の值に対して $A, B, C$ とどう対応づける かは自由なので，(1)式を $A, B, C$ について対称化してお かねばならない，粒断面の $s$ 及び $t$ に関して，それぞれの 平均値及びばらつきを再現するには少なくとも，それに対 応して 4 個の独立なパラメーターを導入すべきである. この意味でここで仮定した分布は最低限必要とされるレべ ルのものである.

\section{3. 結果と考察 $\left(\mathrm{Al}_{2} \mathrm{O}_{3}\right.$ 焼結体への適用)}

2 章で述べた方法を，前述の 2 個の試料に適用した。そ の断面 SEM 写真を図 3 に示す. 長半径と短半径 $(a, b)$ を計測する際，十分に判別できる大きさ以下のもの，すな

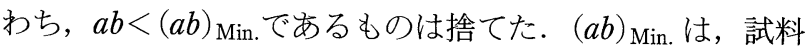
$\mathrm{A}$ で $0.057(\mu \mathrm{m})^{2}, \mathrm{~B}$ で0.27 $(\mu \mathrm{m})^{2}$ とした（写真上で同じ大 きさになる). 全データ数は, 順に943個, 566個である. 得られた $s$ に関する Observed Histograms が図 4, $t$ に関 するものが図 5 である. 同時に Calculated Histograms も 示してある. ヒストグラムのランクは $s, t$ についてそれぞ れ4.6から0.2きざみ，0.0から0.1きざみにとってある.た だし, 長さの単位は画像処理装置のメッシュサイズ (pixel)である. 計算に用いた分布パラメーターは, $\langle s\rangle,\langle(s-$ $\left.\langle s\rangle)^{2}\right\rangle,\langle t\rangle,\left\langle(t-\langle t\rangle)^{2}\right\rangle($ ここで〈s〉は $s$ の平均值を表す. ただし $a b>(a b)_{\text {Min. }}$.の粒子に関して平均する) を実デー タより算定した值に一致するように, 収束計算により決め た. その值は表 1 に示す。 また，インターセプト法で求め た平均インターセプト長も示した. なお，この解析に掞い ては, 焼結体側面における HP 軸と粒断面の長軸のなす 角の分布を計測した結果, 配向性の影響は小さいと考え, 

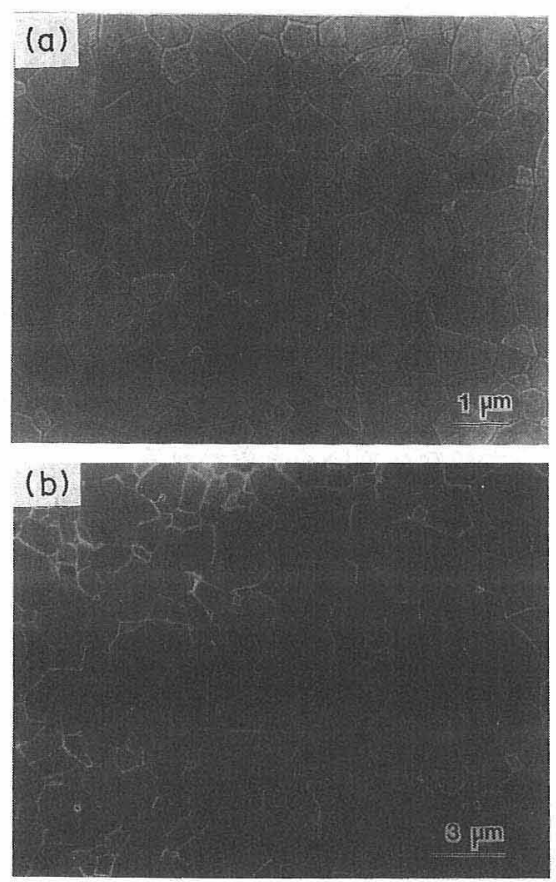

Fig. 3. SEM photographs for the cross-sections of sintered alumina body. (a) $\alpha-\mathrm{Al}_{2} \mathrm{O}_{3}$ and (b) $\gamma-\mathrm{Al}_{2} \mathrm{O}_{3}$.
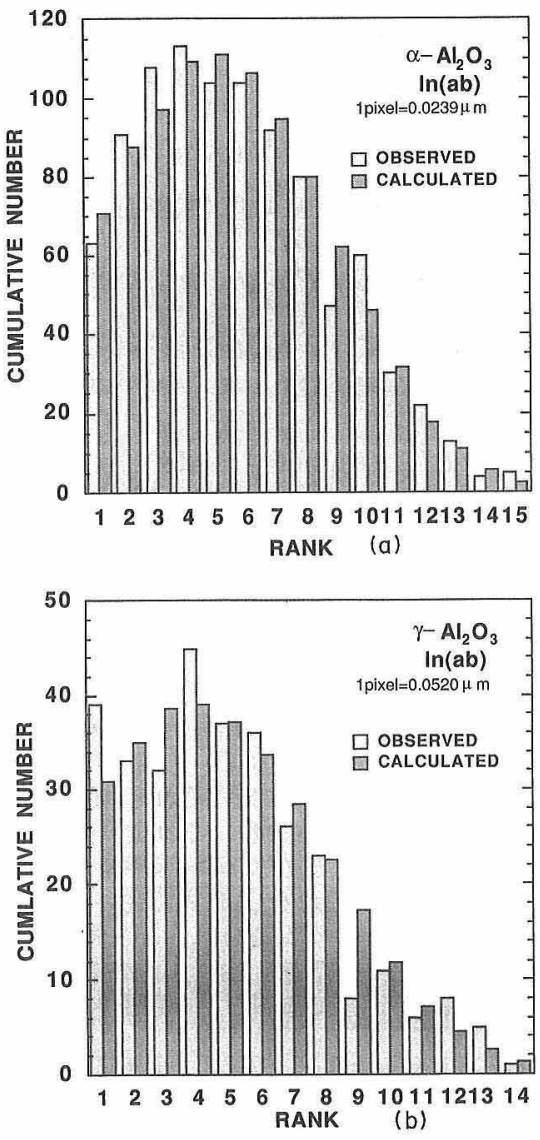

Fig. 4. Histograms of $s=\ln (a b), a$ and $b$ are the long and the short radii of the grain cross-section. Rank interval is 0.2 and the minimum of $s$ is 4.6. Used unit is pixel.

\section{無視した.}

Observed Histograms と Calculated Histograms は定性
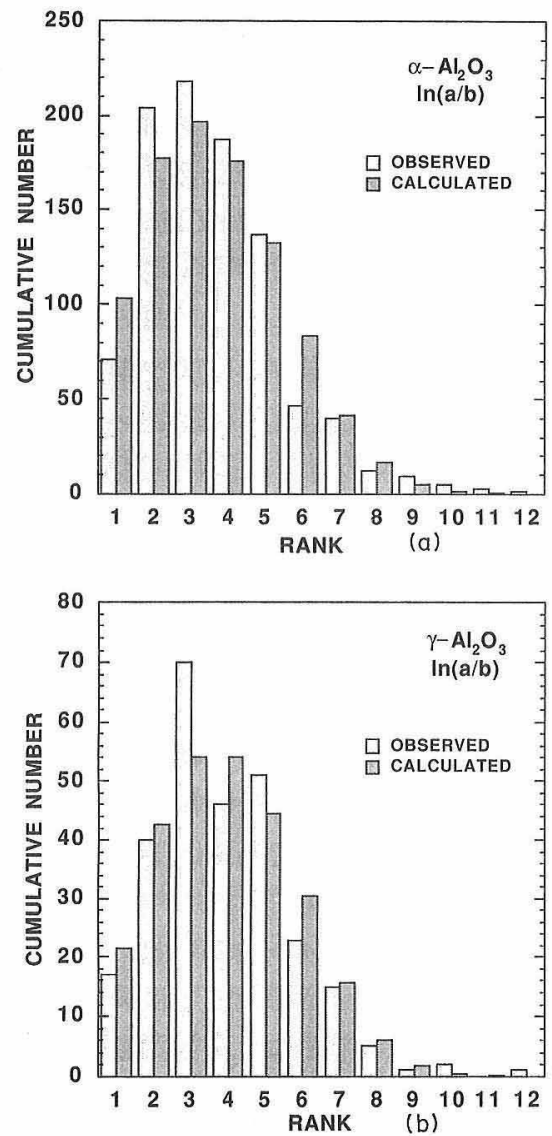

Fig. 5. Histograms of $t=\ln (a / b) . a$ and $b$ are the long and the short radii of the grain cross-section. Rank interval is 0.1 and the minimum of $t$ is 0.0 .

Table 1. Determined distribution parameters. $\bar{L}$ is the average intercept length.

\begin{tabular}{cccccc}
\hline \hline & $\mathrm{v}_{0}{ }^{\frac{1}{3}}$ & $\sigma_{\mathrm{V}}$ & $\mathrm{Q}_{0}$ & $\sigma_{\mathrm{Q}}$ & $\bar{L}$ \\
\hline$\alpha-\mathrm{Al}_{2} \mathrm{O}_{3}$ & $0.40(\mu m)$ & 1.0 & 0.68 & 0.26 & $0.63(\mu \mathrm{m})$ \\
$\gamma-\mathrm{Al}_{2} \mathrm{O}_{3}$ & $0.67(\mu m)$ & 1.1 & 0.63 & 0.25 & $1.20(\mu \mathrm{m})$ \\
\hline \hline
\end{tabular}

的には一致しており，焼結体断面での粒断面の面積及び軸 比の分布が(1)式の形の粒子分布から，ほぼ再現されるこ とが分かった。計測した分布 (Observed Histograms) が，仮定した分布関数により計算した期待値（Calculated Histograms） と矛盾しないかどうかはカイ 2 乗検定 により判定することができる. カイ 2 乗の值は, 試料 $\mathrm{A}$ の $s, t$ についてそれぞれ12.4 (ランク 1 13), 34.5 (ラン ク $1 \sim 8$ ), 試料 Bの $s, t$ についてそれぞれ17.4（ランク 1〜11), 10.8 (ランク 1〜8)であった。これによると特に 試料 $\mathrm{A}$ の $t$ につてのヒストグラムのずれが顕著である. （自由度 $n=7$ の $\chi^{2}$ 分布に扔いて $\mathrm{P}\left(\chi^{2}<\chi_{0}{ }^{2}=95 \%\right.$ ととる と $\chi_{0}^{2}=14.1$ であり $\left.14.1<34.5\right)$ これは, 本研究で仮定し 
た(1)式の分布の帰結としてObserved Histograms を説明 できるとすると矛盾することを示している．しかし，定性 的には一致して抢り，(1)式に修正を加えるならば，本研 究の手法で定量的にも満足のいく一致が可能であると考え ている. Observed Histograms は Calculated Histograms に比べて，よりシャープなピークをもち，かつまたテール を引くようである.

$Q_{0}<1$ は, 平均的な粒形状が，ミカン型であることを示 している．2 個の試料において，粒径の及ならず，この $Q_{0}$ の値の違いが顕著であるが，これは試料 B の粒子が， より偏平な形状であることを示している。 なお $Q_{0}>1$ で は， $t=\ln (a / b)$ のヒストグラムを計算すると, $t=0$ で ピークを持ち Observed Histograms は再現できない。ま た $V_{0} 1 / 3$ がかなり違うにもかかわらず，ばらつきのパラ メーター $\sigma_{V}, \sigma_{Q}$ は，ほとんぞ違いがない。

従来のインターセプト法によって測られる平均インター セプト長 $\bar{L}$ は, 「単位体積当たりの粒界面積の逆数 $\times 2 」$ と いう量であり ${ }^{3)}$ ，適当な一定の補正因子 $k$ を乗じれば，平 均粒径が得られると考えられている4). 補正因子 $k$ の值を ぞう取るべきかについて，種々論じられてはいるが，そこ では粒形状や粒径のばらつきに対しては適当に仮定してし まっている，本研究は，そのような仮定を用いずに粒断面 に関するヒストグラムから, 平均粒体積, 粒体積のばらつ き, 平均粒形状，粒形状のばらつきに対応するパラメ一 ターを同時に求める試みである. 平均粒径を $\bar{D}$ を $\bar{D}=$ $2 V_{0}^{1 / 3}$ で定義すれば， $k$ の值は表 1 より分かるように試料 $\mathrm{A}, \mathrm{B}$ についてそれぞれ1.27，1.12であり，かなりの差違が ある.このことから，著者らは平均インターセプト長 $\bar{L}$ に「単位体積当たりの粒界面積の逆数 $\times 2$ 」以上の意味づ けをするのは困難であると考えている.

データの誤差が，OHP シートに写すとき及び画像処理 装置による計測のときに発生する. 計測の後, 線幅による 補正を加えたが，誤差の大きさは明確にできなかった。よ り現実的な粒子の分布関数を検討するには，まず，この誤 差が十分小さいことが保証でき，かつ大量のデータを計測 する方法の開発が重要であると思われる. また同時に, 「どのような分布関数の形を仮定すべきか？」について も，焼結過程でどのような分布をとりうるかの考察に基づ いた検討をしなければならない。

針状粒子からなる $\mathrm{Si}_{3} \mathrm{~N}_{4}$ 焼結体等，他種の燒結体におい ても本研究で用いた解析の手法は有効であろうと考光る が,

（I）粒子の形状及び，それを規定するパラメーター，

（II）数個の分布パラメーターを持つ分布関数の形, に関する仮定について，修正を要する可能性がある。

\section{4.まとめ}

粒子の体積と軸比に関する分布関数を 4 個の分布パラ メーターを持つ適切な形に仮定し，それから計算される粒 子断面の面積, 軸比分布が現実のものと一致するように,
分布パラメーターを決定した。ここで決定された分布パラ メーターは, 従来のインターセプト法で測られる「平均粒 径」に比して，より詳細に粒度・軸比分布を規定する「組 織の指数」である.

仮定した分布関数の形は自然な形ではあるが，パラメー ターを増やす等の改善も考えられる．その評価には断面写 真の画像処理技術の向上による大量のデータ収集が必要で ある．これが可能になれば，本研究のような手法で分布関 数を更に詳細に論ずることが可能になり，種々の物性值と の相関も明らかになっていくと思われる.

\section{付録，プログラムの作成}

4 個の分布パラメーターから，焼結体断面での粒断面のヒスト グラムを計算するプログラムを作成した，その方法を述べる。

（1）だ円体の方程式は,

$$
\left(\frac{x}{A}\right)^{2}+\left(\frac{y}{B}\right)^{2}+\left(\frac{z}{C}\right)^{2}=1
$$

と書ける.

このだ円体をオイラー角 $(\varphi, \theta, \psi)$ を用いて回転してやることで 任意の空間的方位を得ることができる. $z=l$ 平面との交点の軌跡 はだ円をなすが， $\varphi$ 回転は平面とだ円体の相対的位置関係を变え ないので $\varphi=0$ として，その方程式は,

$$
\begin{aligned}
& \left(\frac{x \cos \psi-y \sin \psi \cos \theta+l \sin \psi \sin \theta}{A}\right)^{2} \\
& +\left(\frac{x \sin \psi+y \cos \psi \cos \theta-l \cos \psi \sin \theta}{B}\right)^{2} \\
& +\left(\frac{y \sin \theta+l \cos \theta}{C}\right)^{2}=1
\end{aligned}
$$

である。これを用いて， $\theta, \psi, l$ に対して粒断面のだ円の長半径 $a$, 短半径 $b$ を計算することができる。

(2) $L^{2} \times L$ の立方体の空間内に $A, B, C$ で指定されるだ円体 粒子が，ランダムに $N$ 個分布しているとする．その立方体の底 面と粒子の相対的位置関係は，その面と粒子中心間の距離を $l$ 々 して, $(l, \theta, \psi)$ により指定される. $N$ 個のうち $\mathrm{d} l \mathrm{~d} \theta \mathrm{d} \psi$ 中にある 粒子の数 $\mathrm{d} N$ は,

$$
\mathrm{d} N=N \times\left(\frac{\mathrm{d} l}{L}\right) \times\left(\frac{\sin \theta \mathrm{d} \theta}{2}\right) \times\left(\frac{\mathrm{d} \psi}{2 \pi}\right)
$$

と表される．単位面積当たりでは，これを書きかえて，

$$
\frac{\mathrm{d} N}{L^{2}}=\frac{N}{L^{3}} \times\left(\frac{l_{\mathrm{M}} \mathrm{d} \nu \mathrm{d} \omega \mathrm{d} \psi}{4 \pi}\right)
$$

と書ける．ただし，ここで $\theta, \psi$ の棈円体の $z$ 軸方向長さを $2 l_{\mathrm{M}}$ $(A, B, C, \theta, \psi$ の関数である $), \omega=l / l_{\mathrm{M}}, v=-\cos \theta$ とした。

(3) 粒子のパラメーター $(A, B, C)$ の乱数を(1) 式に従うよ う発生させる。 また， $v, \omega, \psi$ についてはそれぞれ区間 $(-1,1),(-1$, 1), $(0,2 \pi)$ の一様乱数を発生させる. これより，(1)で述べたよ うに $A, B, C, v, \omega, \psi$ の関数として $a, b$ を計算することができ る. 同様に $l_{\mathrm{M}}$ も計算する。 これを(A4)式に従い $l_{\mathrm{M}}$ のウエイトを 考え積算することでヒストグラム等を得ることができる．発生さ せた乱数は全部で $10^{5} セ ッ ト て ゙ あ り ， 5 \times 10^{4}$ セットの場合と比較 することで乱数発生数が十分であることを確認した.

（1992年 1 月第30回セラミックス基礎科学討論会発表）

\section{文献}

1) E.E. Underwood, "Quantative Stereology", Addison-Wesley (1970) pp. Chap. 4 and 5.

2) R. T. DeHoff, Trans. Metal. Soc. AIME, 224, 474-75 (1962).

3) JME, "The Journal of Material Education" Vol. 4 (1982) No. 2 ,「セラミックスの微構造」, 大津賀 望, 中川善兵衛, 岡 田 清編訳, 内田老鶴國 (1986) 第 1 章.

4) M. I. Mendelson, J. Am. Ceram. Soc., 52 ,443-46 (1969). 